\begin{tabular}{|c|l|}
\hline Title & Steps in lithospheric thickness within eastern A ustralia, evidence from surface wave tomography \\
\hline Author(s) & Fishwick, S.; Heintz, M.; Kennett, B. L. N.; Reading, A. M.; Y oshizawa, K. \\
\hline Citation & $\begin{array}{l}\text { Tectonics, 27(4), TC4009 } \\
\text { https://doi.org/10.1029/2007T c002116 }\end{array}$ \\
\hline Issue Date & 2008-08 \\
\hline Doc URL & http://hdl.handle.net/2115/52171 \\
\hline Rights & Copyright 2008 A merican Geophysical Union. \\
\hline Type & article \\
\hline File Information & tect1939.pdf \\
\hline
\end{tabular}

Instructions for use 


\title{
Steps in lithospheric thickness within eastern Australia, evidence from surface wave tomography
}

\author{
S. Fishwick, ${ }^{1,2}$ M. Heintz, ${ }^{1,3}$ B. L. N. Kennett, ${ }^{1}$ A. M. Reading,,${ }^{1,4}$ and K. Yoshizawa ${ }^{5}$ \\ Received 29 January 2007; revised 8 January 2008; accepted 7 April 2008; published 1 August 2008.
}

[1] A series of steps in the lithospheric thickness of eastern Australia are revealed by the latest seismic surface wave tomographic model and calculations of the horizontal gradient of shear wave speed. The new images incorporate data from the recent Tasmal experiment, improving resolution in continental Australia. Through comparisons with surface geology and geochemical studies, it is possible to infer that the steps in lithospheric thickness are related to boundaries between blocks of different age. The westernmost boundary marks the edge of the Archaean to Early-Proterozoic core of the continent. A second lithospheric boundary is observed in the central part of east Australia. To the west of this line, geochemical evidence suggests that there is Proterozoic lithospheric mantle, and this boundary may therefore represent the change from Proterozoic to Phanerozoic basement. The structure on the eastern margin of the continent is dominated by slow velocities, suggesting that in this area the continental lithosphere is very thin. There is a strong correlation between the slow wave speeds and the location of both the highest topography and recent volcanic activity. Inland of the continental margin, a zone of strong gradients in the seismic wave speed is observed, indicating a distinct step in lithospheric structure. If the step in lithospheric thickness was in place prior to volcanism, it may have acted as a boundary, with volcanism mainly occurring beneath the thinner lithosphere to the east. Citation: Fishwick, S., M. Heintz, B. L. N. Kennett, A. M. Reading, and K. Yoshizawa (2008), Steps in lithospheric thickness within eastern Australia, evidence from

\footnotetext{
${ }^{1}$ Research School of Earth Sciences, Australian National University, Canberra, ACT, Australia.

${ }^{2}$ Now at Department of Geology, University of Leicester, Leicester, UK

${ }^{3}$ Now at Bullard Laboratories, Department of Earth Sciences, University of Cambridge, Cambridge, UK.

${ }^{4}$ Now at School of Earth Sciences and Centre of Excellence in Ore Deposit Research, University of Tasmania, Hobart, Tasmania, Australia.

${ }^{5}$ Department of Natural History Sciences, Faculty of Science, Hokkaido University, Sapporo, Japan.
}

Copyright 2008 by the American Geophysical Union. 0278-7407/08/2007TC002116 surface wave tomography, Tectonics, 27, TC4009, doi:10.1029/ 2007 TC002116.

\section{Introduction}

[2] The Australian continent is comprised of a large shield region in central and west Australia, consisting of an amalgamation of blocks of Archaean and Proterozoic age, with younger Phanerozoic terranes in the east (Figure 1). The seismic velocity structure of the Australian lithosphere is dominated by a strong contrast in the wave speeds of the old and young regions. Data from nuclear explosions indicated negative, fast, travel time anomalies within the shield areas, and positive, slow, anomalies in south-eastern Australia [Cleary, 1967]. Using data from temporary broadband deployments, surface wave studies have also shown this difference in wave speed between the two regions [e.g., Zielhuis and van der Hilst, 1996; van der Hilst et al., 1998; Simons et al., 2002; Debayle and Kennett, 2003; Yoshizawa and Kennett, 2004; Fishwick et al., 2005].

[3] Recently, discussion has focused on the contrasts in shear wave speed beneath the different cratons that form the shield [Fishwick et al., 2005] and the variations in thickness of the lithosphere between regions of different ages [Simons and van der Hilst, 2002]. Kennett et al. [2004] investigated the seismic velocities in the vicinity of the Tasman Line, the eastern boundary of the Precambrian outcrop, using data from both body waves and surface waves. A dividing line at approximately $140^{\circ} \mathrm{E}$ marked the edge of the thickest coherent lithosphere, and the analysis of the surface wave tomography suggested there may be a series of steps in the thickness of the lithosphere. In earlier work using surface wave dispersion data, a low-velocity zone on the eastern edge of Australia was observed at approximately $130-\mathrm{km}$ depth [Goncz and Cleary, 1976]. In this region low velocities have also been observed in the tomographic studies and Zielhuis and van der Hilst [1996] noted the correlation between the lowest velocities and the volcanic areas in eastern Australia.

[4] More detailed studies in eastern Australia have been undertaken using dense networks of short-period seismometers and body wave tomography. The teleseismic tomographic study of Graeber et al. [2002] indicates a sharp contrast in $\mathrm{P}$ wave speed at the boundary between the Delamerian and Lachlan Orogens, and slow velocities associated with a thermal anomaly in the region of the Newer Volcanic Province (see Figure 1 for locations). Further north, data from a recent network of seismometers (seal) have been used in a teleseismic tomographic study of the structure of the upper mantle [Rawlinson et al., 2006]. 

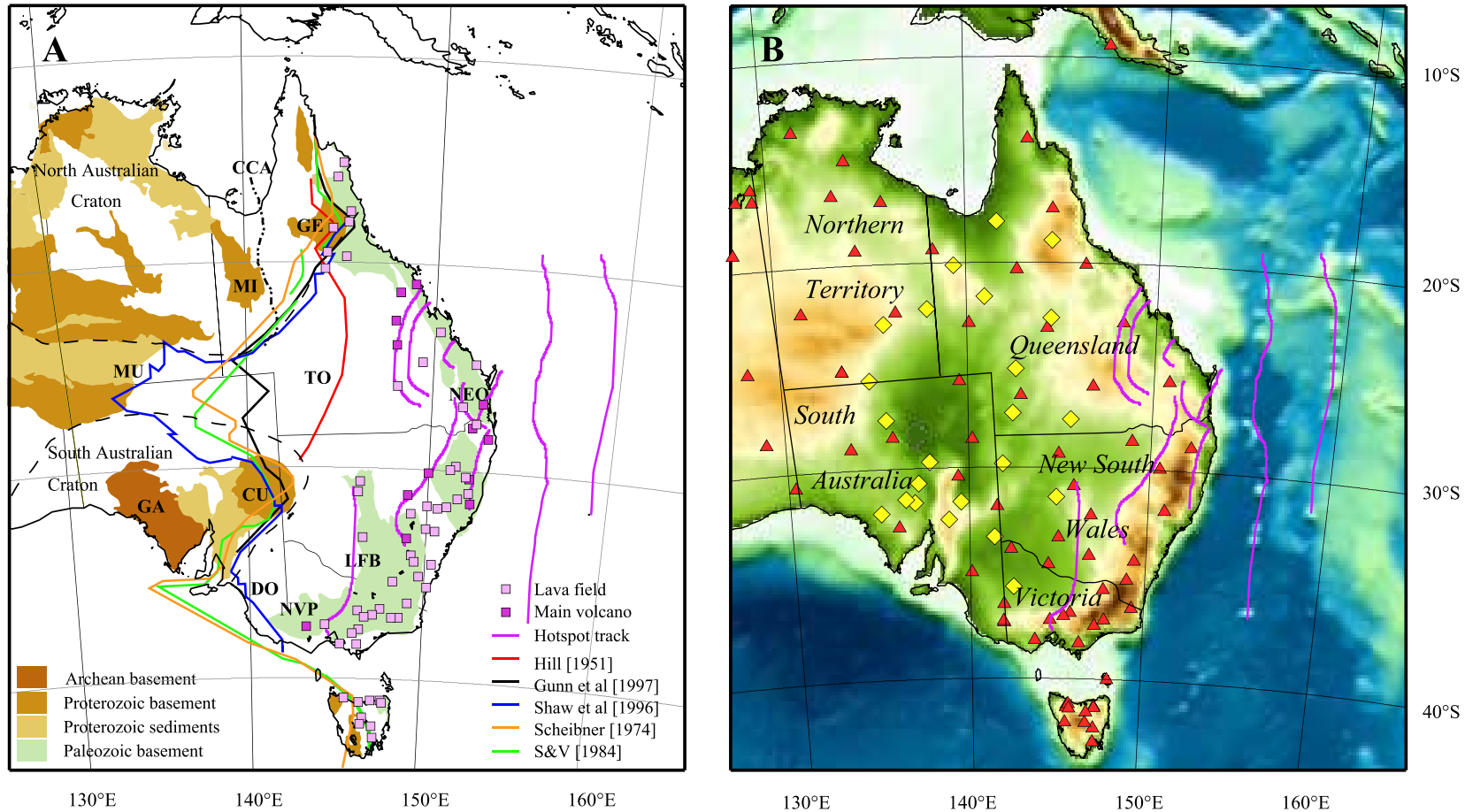

Figure 1. (a) Key map for the geological setting: CCA, Carpentaria Conductivity Anomaly; GE, Georgetown Inlier; MI, Mt. Isa Block; TO, Thompson Orogen; NEO, New England Orogen; LFB, Lachlan Fold Belt; NVP, Newer Volcanic Province; DO, Delamerian Orogen; CU, Curnamona Block; GA, Gawler Craton; MU, Musgrave Block. Precambrian crust is shown in shades of brown and Phanerozoic basement in light green. The purple lines mark hotspot tracks by Sutherland et al. [2003]. Pink and purple squares show the location of volcanic activity summarized in Finn et al. [2005]. The other colored lines mark the locations of proposed Tasman Lines. (b) Topography and bathymetry of the Australian continent and surrounding sea. Location of the broadband seismometers used for this work. The red diamonds indicate the locations of the instruments deployed in the Tasmal experiment; data from these instruments have not previously been used in the construction of tomographic models of Australia. Hotspot tracks are again shown with purple lines.

The authors find a similar sharp contrast at the boundary of the Delamerian and Lachlan Orogens, but also indicate more varied structure further east.

[5] Data from a temporary deployment of twenty broadband seismometers (Tasmal, 2003-2005) located in the vicinity of the Tasman Line (Figure 1) are now available and improve the resolution at the edge of the Australian Craton and throughout Eastern Australia. Incorporating all data from this project in the surface wave inversion, we produce improved tomographic images of the Australian region. The tomographic models can be used to give insights into the structure of the lithosphere.

[6] The concept of the lithosphere is somewhat varied depending on the approach taken when investigating the Earth's structure. Originally the term was used to define the strong outer layer of the Earth [Barrell, 1914]. It is now used in relation to a thermal boundary layer (thermal lithosphere), a chemical boundary layer (chemical lithosphere) and also for the support of long-term stresses (effective elastic thickness) [see, e.g., White, 1999, for further discussion]. Although there are a number of different approaches relating a tomographic model to physical prop- erties of the upper mantle [e.g., Faul and Jackson, 2005; Goes et al., 2005; Priestley and McKenzie, 2006], taking the simple qualitative approach suggests that fast wave speeds in the uppermost mantle are associated with lower temperatures, and can be used to define regions with thick lithosphere.

[7] Using the new tomographic models, and in conjunction with a technique assessing the horizontal gradients of the shear wave speed models [Fishwick, 2006], we now have an improved method to investigate the lateral variations in structure in the uppermost mantle of eastern Australia. Combining the information from the tomographic models with geological and geochemical observations allows the relationship between the changes in shear wave speed structure and the overlying geology to be discussed in detail. The improved station coverage of the Tasmal deployment also allows us to consider the influence of azimuthal anisotropy on the surface wave tomographic images. These results give better constraints on the nature of the transition between the thickest coherent lithosphere of the shield region and the younger eastern terranes, more information on the basement in regions with limited out- 
crop, and on the impact of pre-existing lithospheric architecture on the location of recent volcanism.

\section{Tectonic Setting}

[8] The tectonic history and evolution of eastern Australia is related to a succession of orogenic events, progressively younging toward the eastern edge of the continent. The Tasman Line is sometimes used to describe the western limit of the younger terranes, but the concept and interpretation of this line has had a long and varied history [Direen and Crawford, 2003; Kennett et al., 2004]. Uncertainty on the age of the basement beneath much of eastern Australia remains due to a paucity of outcrop. The key features of the region are discussed below (refer to Figure 1a for locations of places discussed in the text).

\subsection{Tasman Line}

[9] The earliest definition of the Tasman Line by Hill [1951] was based on outcrop and defined the boundary line between the craton and geosyncline in early Palaeozoic times (red line, Figure 1a). Alternative interpretations of the Tasman Line have been made using gravity and magnetic lineaments [e.g., Scheibner and Veevers, 2000; Gunn et al., 1997], and these lineaments have been associated with the break up of the Rodinian supercontinent at c. 780 Ma. Direen and Crawford [2003] give a thorough review of the history behind interpretations of the Tasman Line. They present geological and geophysical evidence that suggests that the lineaments defining the Tasman Line are in fact a result of a number of events of different ages. It appears that there is no simple 'line' defining one single tectonic event.

[10] In northern Australia, all the representations of the Tasman line are in broad agreement, and follow the eastern limit of Precambrian rocks seen within Australia (see Figure 1). From dating of orogenic events, and their apparently contemporaneous history, the Georgetown Inlier has been correlated with the Mt Isa block and is therefore included as part of the North Australian Craton [e.g., Betts et al., 2002; Giles et al., 2002]. In contrast to the interpretations of the Tasman Line, results from resistivity studies highlight a structure (Carpentaria Conductivity Anomaly) that may represent a major suture at the eastern boundary of the Mt Isa Block. Boger and Hansen [2004] have also suggested that there are differences in the metamorphic history and crustal evolution of the regions, implying that the Georgetown Inlier could have been a separate lithospheric block from the rest of the North Australian Craton.

[11] In southern Queensland the geological foundations of any Tasman Line are less certain; much of the area is obscured by recent sedimentary cover. Due to the lack of outcrop, the inferred locations of the Tasman Line are predominantly based on images of the magnetic anomalies, and have an indentation to the west. The crustal element map of Shaw et al. [1996] has the furthest indent, using both the geophysical signatures and the location of surface outcrop to define its boundary (blue line in Figure 1a). In this region the modern interpretations of the Tasman Line differ greatly from the original line proposed by Hill [1951]. Further south, the proposed Tasman Lines then continue to the east of the Curnamona block. While the majority of the Curnamona block is covered by shallow sediments, it is delineated by aeromagnetic data. Correlations in the geological features of the Curnamona Province and the eastern Mt Isa Block suggest they were in close proximity during the Palaeo-Mesoproterozoic. Giles et al. [2004] propose a reconstruction that places these regions adjacent until approximately $1.5 \mathrm{Ga}$.

\subsection{East Australian Orogens}

[12] The Delamerian Orogeny was associated with convergence along the proto-Pacific margin of the continent. Alongside folding and metamorphism of the Adelaidean succession, the Delamerian Orogeny also caused overprinting of the basement units of the Curnamona and Gawler Cratons. Remnants of crustal material, formed in the Cambrian-Ordovician, are preserved within the Lachlan Fold Belt to the east of the Delamarian Orogen. The setting of the Lachlan Orogen is thought to be the back arc of a west dipping subduction zone. However, there is ongoing debate as to the exact causes and nature of the accretion, with Foster and Gray [2000] linking deformation to multiple subduction systems, while Glen [2005] suggests accretion was dominated by transpressive motion. The New England Orogen, on the eastern margin of the continent, is a series of northnorthwest trending belts, representing the varied geology of the convergent margin: volcanic arc, fore-arc/back-arc basins and subduction assemblages [Betts et al., 2002].

[13] A key question in the structure of eastern Australia is the nature of the basement beneath the accretionary assemblages. The geochemistry of mantle xenoliths provides an insight into the age of the subcontinental lithospheric mantle. Using Re-Os isotopic data, McBride et al. [1996] found evidence of Proterozoic lithosphere beneath western Victoria. Handler and Bennett [2001] investigated the age of the lithospheric mantle from five localities in southeast Australia. The Os isotopic data suggests that Proterozoic lithospheric mantle extends further east than the Tasman Line, with a rapid change indicating a lithospheric-scale boundary which lies between the Delamerian and Lachlan Fold Belts [Handler and Bennett, 2001]. Beneath the majority of the Lachlan Orogen the general consensus is that the basement was predominantly oceanic lithosphere [Gray and Foster, 2004; Glen, 2005]. However, it remains a possibility that there are fragments of continental basement, which have been attached in the orogenic events [Cayley et al., 2002]. Substrate beneath the New England Orogen is a mixture of oceanic and continental, and a number of lines of evidence point to the persistence of old lithosphere in some regions [Glen, 2005].

\subsection{Eastern Margin of the Continent}

[14] The topography of eastern Australia is dominated by the Eastern Highlands, along the eastern margin of Australia. The cause and timing of the uplift of the Eastern Highlands is still a focus of debate. Lambeck and Stephenson [1986] proposed that the present elevation was not due to recent 


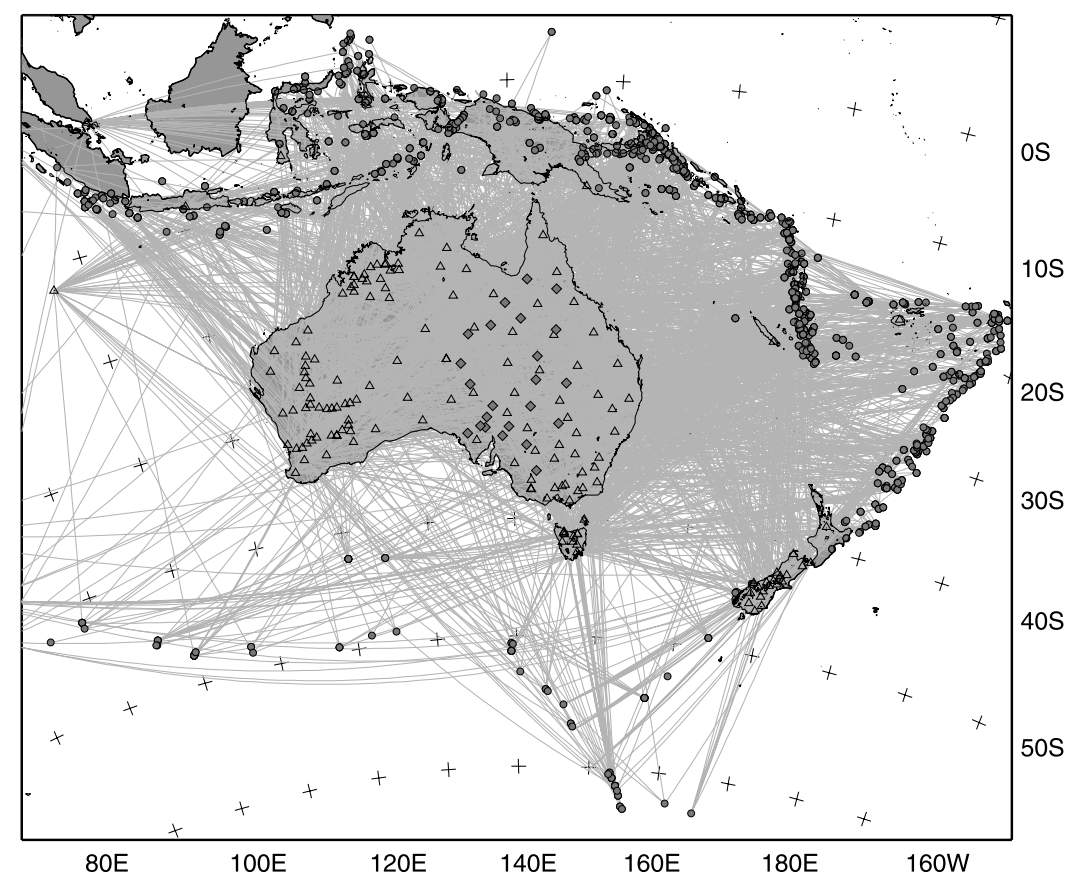

Figure 2. The maximum path coverage used in this study (at periods of 50-80s), events are shown with circles, the location of broadband seismometers are shown with triangles, or diamonds for those instruments deployed in the Tasmal experiment.

uplift, but is the remnant of a larger Palaeozoic mountain belt, whereas Wellman [1987] suggested that the initiation of uplift was in the mid-Cretaceous, and recent uplift was caused by crustal underplating associated with Cenozoic basaltic volcanism. A possible explanation for the initial uplift in the mid-Cretaceous is given by Lister and Etheridge [1989]; removal of lithosphere and igneous underplating caused by the rifting of the Tasman Sea and asymmetric passive margin formation create uplift on the upper plate. However, recent work combining apatite fission track and (U-Th)/He analyses indicates that the margin of Australia experienced rapid denudation starting at $110 \pm 10 \mathrm{Ma}$, at least 15 Ma before sea floor spreading [Persano et al., 2005]. Using fission-track data and numerical modeling of surface processes, van der Beek et al. [1999] also find that the drainage and denudation history of the southeastern part of the Eastern Highlands can, to first order, be explained without invoking mid-Cretaceous or more recent uplift. In contrast, a detailed local study of one region of the southeastern highlands, indicates episodes of denudation in both the Early to Late Triassic (246-220 Ma) and also in the Late Cretaceous to Early Tertiary (70-50 Ma) [O'Sullivan et al., 2000]. It appears that there is a complicated uplift history along the eastern margin of the continent, where locally denudation has occurred at various times.

[15] The eastern margin of Australia has also experienced relatively extensive volcanism [e.g., Johnson, 1989]. While there is some Mesozoic volcanism, the majority is dominantly Cenozoic in age and often related to the East Australian Plume System [e.g., Wellman, 1983]. Older volcanism (c. $65 \mathrm{Ma}$ ) is found in northern Queensland, with progressively younger ages found further south. The
Mount Gambier region of the Newer Volcanics, near the South Australia-Victoria border has been active as recently as 4600 years ago [Johnson, 1989]. Sutherland [2003] attributes the bends, or "boomerangs", in the East Australian Plume System hotspot tracks to peaks in plume activity and dynamic flow in the mantle. Although the progressive volcanism in eastern Australia and the Tasman Sea is consistent with passage over a hot spot, there is still some uncertainty over the cause of the volcanism. Very low velocities have been imaged beneath much of the southwest Pacific and Finn et al. [2005] define a large region as a Diffuse Cenozoic Alkaline Magmatic Province (DAMP). They associate much of the Cenozoic volcanism in this region with the detachment of subducting slabs in the late Cretaceous.

\section{Surface Wave Tomography}

[16] Over the period 2003-2005, more than 20 broadband seismometers were installed in central and eastern Australia (Figure 1b), in order to bracket the location of the proposed Tasman Lines and provide data to further investigate the structure of the edge of the shield region. A variety of portable instruments have been deployed during the experiment: Güralp CMG-40T, CMG-3ESP+, Nanometrics Trillium and Streckeisen STS-2 seismometers, and a combination of Reftek and Nanometrics recorders. The data from this Tasmal deployment is now included in the surface wave inversion. In comparison to the previous model [Fishwick et al., 2005] the new data add over 500 paths, giving almost a $25 \%$ increase in the total number of paths (Figure 2), thus 
improving the resolution in continental Australia. Some further data have been included from permanent seismic stations to increase the azimuthal coverage. The number of paths into the permanent stations have been deliberately limited to avoid the large concentrations of similar paths into a single station and the possible bias in the tomographic models that this may produce.

\subsection{Method}

[17] Initially, a 1D model for the path between the source and the receiver is calculated using the automated procedure by Debayle [1999], based on the waveform inversion scheme of Cara and Lévêque [1987]. Information from the surface waveform at periods of between 50 and $120 \mathrm{~s}$ for the fundamental and first four higher modes is used to constrain the path average 1D model. The inclusion of higher mode information greatly improves the vertical resolution. These 1D models are defined at $25 \mathrm{~km}$ depth intervals below $50 \mathrm{~km}$ depth; the crustal model remains fixed as the path average structure through the model 3SMAC [Nataf and Ricard, 1996]. In this stage of the inversion process, we use multiple starting models [Fishwick et al., 2005] to improve the reliability of the 1D model. The starting models have different velocities in the upper mantle, variations between -4.5 and $+4.5 \%$ from the reference model PREM [Dziewonski and Anderson, 1981], thus giving a better chance of recovering the path average 1D model in the inversion. The consistency between the group of path average models provides an additional means to assess the reliability of the wave speed profile with depth; the path-specific 1D model used in the tomographic inversion is a weighted average of the similar final models accepted by the inversion scheme.

[18] The final set of 1D models is then used within a tomographic inversion to derive a model of the isotropic velocity structure. In the present inversion a total of 2639 path average models have been defined (Figure 2). The tomographic inversion is used as a method of spatially averaging the $1 \mathrm{D}$ models, in order to locate regions with fast or slow wave speeds. The 1D models are defined at $25 \mathrm{~km}$ intervals, and at each depth a 2D model is independently calculated. The reconstruction of the $2 \mathrm{D}$ model at a particular depth can be achieved by a linear inverse problem relating the velocity perturbation at a particular point to the path information at the same depth. The data (d) are the fractional shear-wave perturbation, $\langle\delta \beta\rangle / \beta_{0}$, from the reference model of the path average velocity along the path at the particular depth for which we are constructing the model. At a given depth, a path-average perturbation of shear wave speed can be represented by an integration of local shear wave speed perturbations $\delta \beta$ along a great circle as follows,

$$
\frac{\langle\delta \beta\rangle}{\beta_{0}}=\frac{1}{\Delta} \int_{\text {g.c. }} \frac{\delta \beta}{\beta_{0}} d s
$$

where $\Delta$ is the length of the path, and the integration is taken along a great circle path.
[19] The shear wave speed distribution can be expanded in a set of spherical B-spline functions $\mathcal{F}(\theta, \phi)$ [e.g., Wang and Dahlen, 1995] as employed in a previous work on the Australian structure by Yoshizawa and Kennett [2004]. The fractional perturbations of shear wave speed can then be represented as follows,

$$
\frac{\delta \beta(\theta, \phi)}{\beta_{0}}=\sum_{j}^{N} m_{j} \mathcal{F}_{j}(\theta, \phi)
$$

where the coefficient $m_{j}$ of the $j$ th basis function $\left(\mathcal{F}_{j}\right)$ is the component of model parameter vector $\mathbf{m}$, which is to be determined through the inversion, and $N$ is the total number of model parameters. The use of the spherical B-spline basis functions allows us to incorporate a Gaussian type smoothing around the knot point. The detailed description of the model parameterization based on the spherical B splines is fully explained by Yoshizawa [2002].

[20] With the B-spline functions, the components of the kernel matrix $\mathbf{G}$ for the $i$ th path and the $j$ th model parameter can be given as follows,

$$
G_{i j}=\frac{1}{\Delta_{i}} \int_{0}^{\Delta_{i}} d s \mathcal{F}_{j}
$$

where $\Delta_{i}$ is the epicentral distance for the $i$ th path, and the integration is taken along a great circle path. The inversion is then solved using a damped least squares inversion scheme [Paige and Saunders, 1982], where we attempt to minimize the following objective function:

$$
\boldsymbol{\Phi}(\boldsymbol{m})=(\boldsymbol{d}-\boldsymbol{G m})^{T} \boldsymbol{W}_{d}(\boldsymbol{m})(\boldsymbol{d}-\boldsymbol{G} \boldsymbol{m})+\lambda^{2} \boldsymbol{m}^{T} \boldsymbol{m}
$$

[21] The data $(\boldsymbol{d})$ are weighted $\left(\boldsymbol{W}_{d}\right)$ to control the relative contribution of each path based on our estimate of the reliability of the 1D model. The weighting includes information from the waveform inversion procedure and also the similarity of the 1D models produced from the multiple starting models. $\lambda$ is the damping parameter used to control the trade-off between model variance and resolution. In our inversion we are using the damping to control how far from the reference model we allow the final model to deviate. If the damping is large we will minimize the underdetermined part of the solution, but will not minimize the prediction error. If no damping is applied we minimize the prediction error, but no a priori information (the reference model) will be used to single out underdetermined parameters [Menke, 1989].

[22] In a region with large velocity contrasts in the upper mantle, e.g., between cratonic regions and oceans, it is not ideal to damp toward a global reference model, as they are unlikely to be representative of either type of structure. We therefore use a two step inversion scheme [Fishwick et al., 2005] to produce the tomographic images, allowing damping toward large-scale features in the data rather than a global reference model. In the first inversion step, the reference model is a uniform velocity and an inversion for the large-scale structure, with knot points at $6^{\circ}$ intervals is 
performed. In the final inversion step the reference model is now dependent on the path, as it includes the features observed in the initial tomographic inversion, and the knot points are defined at $2^{\circ}$ intervals.

\subsection{Anisotropy}

[23] One of the uncertainties when discussing the results from the isotropic inversion is the impact of any anisotropic structure. Azimuthal anisotropy of Rayleigh waves can be incorporated by modifying the shear wave speed perturbation $\delta \beta$ to include both the isotropic and azimuthally anisotropic terms. In a similar way to Simons et al. [2002], we employ the first-order relation of $\delta \beta$ which can be represented as,

$$
\delta \beta=\delta \beta_{I}+A_{1} \cos 2 \Psi+A_{2} \sin 2 \Psi,
$$

where $\delta \beta_{I}$ is the isotropic perturbation of shear wave speed, and $A_{1}$ and $A_{2}$ are azimuthally anisotropic terms of shear wave speed perturbation, and $\Psi$ is the azimuth of the Rayleigh wave propagation. The coefficients $A_{1}$ and $A_{2}$ relate to the elastic parameters in the anisotropic media, which are discussed in detail by Montagner and Nataf [1986] and Lévêque et al. [1998].

[24] In this study we expand both the isotropic and anisotropic terms of shear wave speed perturbation into the spherical B-spline functions as the case for isotropic inversion described in the previous section. Both isotropic and anisotropic terms are expanded with a knot interval of $2^{\circ}$, giving the same lateral smoothing as in the final stage of the isotropic inversion.

\section{Results}

\subsection{Tomographic Images}

[25] Tomographic images are shown at four depths: 100, 150,200 and $250 \mathrm{~km}$ (Figure 3). The models are plotted as perturbations from the global reference model ak135 [Kennett et al., 1995]. The choice of ak135 rather than PREM, which was used as a starting point for the waveform inversions, is simply for representative purposes. Discussion will be focused on structure beneath the continent and ak135 is based a little more toward a continental model. The same color scale is used at each depth, with saturation occurring at perturbations greater than $\pm 8 \%$.

[26] Within Australia, at $100 \mathrm{~km}$ depth the striking feature is a zone of very slow velocities on the eastern edge of the continent. The velocities on this edge of the continent are similar to much of the region below the sea to the east, but slightly slower than a NS trending anomaly (approx $155^{\circ} \mathrm{E}$, and $17-27^{\circ} \mathrm{N}$ ) which is above the region of the Tasman Sea with oceanic crust of about $60 \mathrm{Ma}$. Inland, slightly faster velocities relative to ak135 are seen throughout most of the region, although these areas of fast shear wave speed are somewhat fragmented between $135^{\circ} \mathrm{E}$ and $145^{\circ} \mathrm{E}$. At $150 \mathrm{~km}$ depth (Figure $3 \mathrm{~b}$ ) the largest variations in shear wave speed are observed, more than $15 \%$ difference between the fastest and slowest regions. Very fast velocities are observed in the central part of Australia, with the very slow velocities continuing on the eastern margin and beneath the Tasman Sea.

[27] In comparison to the images of shallower depths, by $200 \mathrm{~km}$ depth (Figure 3c), a significantly larger proportion of eastern Australia is now underlain by velocities slower than the reference model (ak135). The very distinct band of slow velocities on the margin of the continent is less obvious than at the shallower depths. The majority of the central and western part of the continent is underlain by faster velocities [see also, Fishwick et al., 2005]. By $250 \mathrm{~km}$ depth (Figure 3d), the range in shear wave speed perturbations is much smaller, with wave speed variations of up to $8 \%$ between the fastest and slowest regions. In eastern Australia and beneath the Tasman Sea the wave speeds are generally slightly slower than the reference model, although there are now some regions that also have fast velocities. In central Australia the fast velocities appear to be more fragmented, and in the southern part of the model there are two NW-SE trending bands of faster velocities that are not easily related with the wave speed variations that are observed at the shallower depths.

\subsection{Gradient Models}

[28] In the investigation of lithospheric structure within eastern Australia we are interested in regions of contrasting velocities. An additional tool in the interpretation of tomographic images is to plot the magnitude of the horizontal gradient of the shear wave speed [Fishwick, 2006]. The horizontal gradient will be sensitive to lateral variations in the wave speed, highlighting zones of strong gradient. Gradient mapping is a common technique used in other fields of geophysics, and has recently been used to link lineations in geological structures with areas suitable for diamond exploration [Jaques and Milligan, 2004].

[29] A distinct advantage of the gradient maps, as opposed to the tomographic images themselves, is that they are independent of the reference model. In the tomographic models presented in the previous section, the choice of the reference model is an important factor in the interpretation of the images. The two-tone color scheme, through the transition between colors, draws attention to the change from positive to negative velocities. The position of this apparent boundary is strongly dependent on the choice of the reference model [Fishwick, 2006]. As the images of the horizontal gradient are independent of the reference model they therefore highlight features that may not be evident from the tomographic images alone.

[30] In order to calculate the magnitude of the horizontal gradient, north-south and east-west gradients are first estimated. A centered finite difference approximation over a one degree interval is computed at each point in the region. From the north-south and east-west gradients the magnitude and vectorial information of the horizontal gradient can then be computed [see Fishwick, 2006, for more details].

[31] Figure 4 shows the magnitude of the horizontal gradient at the depths of 100, 150, 200 and $250 \mathrm{~km}$. Lines have been overlain to indicate zones of gradient that are discussed below; the lines are in the same place at all depths 

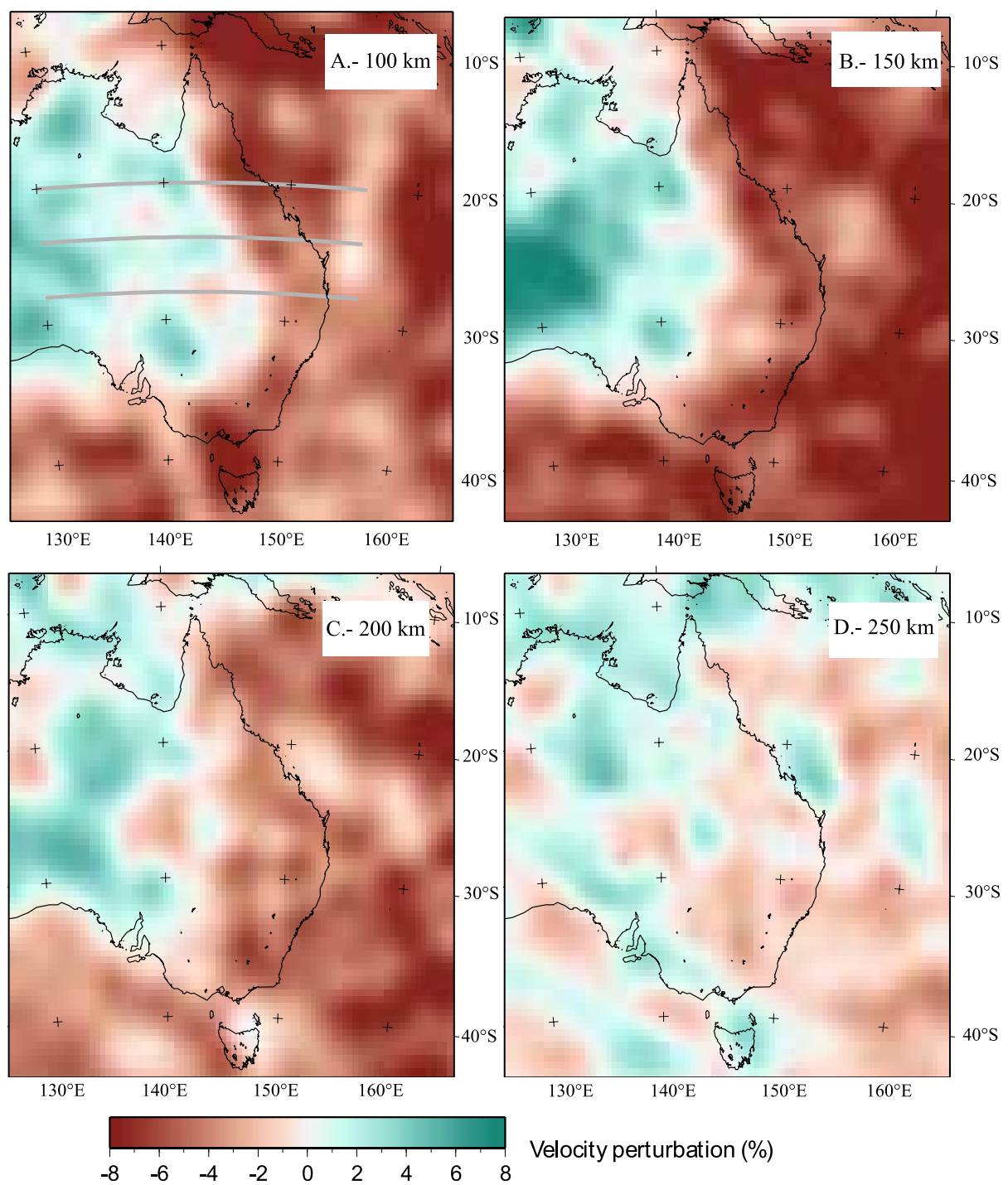

Figure 3. Images showing the isotropic shear wave speed models from the tomographic inversion at $100-, 150-, 200-$, and 250-km depth. The models are plotted as perturbations from the global reference model $a \mathrm{k} 135$, and the color scale remains the same for all images. The solid gray lines show the location of the cross sections plotted in figure.

to give an indication on the vertical coherency of the gradient zones. The strongest continuous gradient is seen toward the eastern margin of Australia in the image at $100 \mathrm{~km}$ (dashed line), hints of this structure continue to at least $150 \mathrm{~km}$ depth. Offshore there are also two bands of strong gradients, which relate to the edges of the NS trending anomaly of slightly faster velocities (Figure 3a) observed beneath this part of the Tasman Sea previously discussed in section 4.1. Further inland, at $100 \mathrm{~km}$ depth, there is little indication of strong gradients.

[32] However, by $150 \mathrm{~km}$ depth (Figure 4b), there are indications of strong gradients within the continental interior of Australia (Figure 4, dotted and dash-dot lines). There are also strong gradients further to the west of any of the proposed Tasman Lines, within the region of fast velocities, but these are not discussed in this work. In the tomographic images the velocity structures appear more fragmented at $250 \mathrm{~km}$ depth (Figure 3d); this is also apparent in the gradient images. The regions of strong gradient are no longer as coherent over a large length scale, and do not show a clear relationship with any of the gradients at shallower depths (Figure 4d).

[33] The solid line indicates a region where there are quite strong gradients at all the depths. The location of this line has predominantly been defined by the gradients at $150 \mathrm{~km}$ depth and marks the edge of a block of faster lithosphere (Figure 3b). By $200 \mathrm{~km}$ depth the edge of this region does not have strong gradients on all sides, with the 

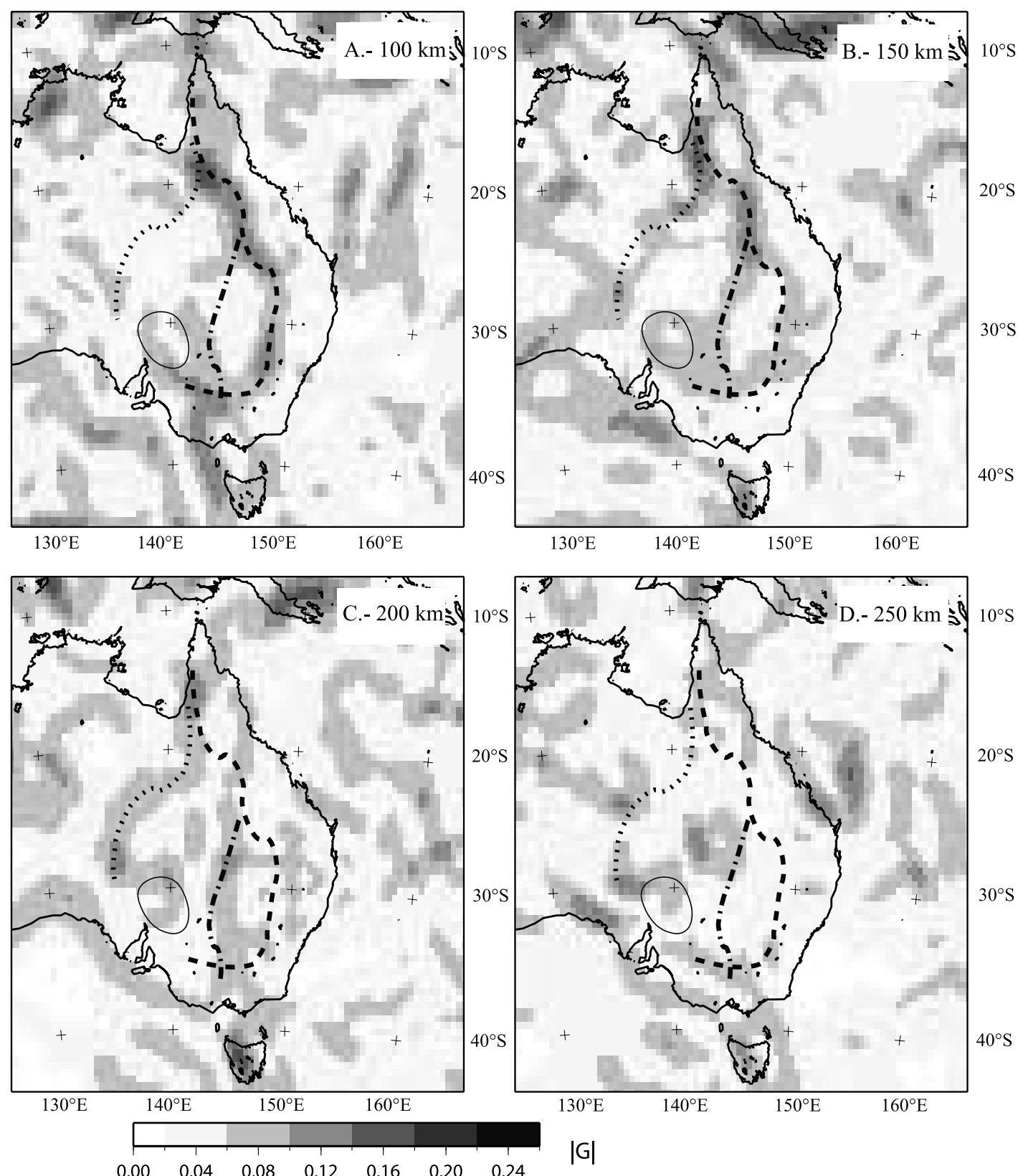

Figure 4. Images showing the magnitude of the horizontal gradient $\mathrm{G}$ of the shear wavespeed at 100-, 150-, 200-, and 250-km depth. The four lines (solid, dotted, dashed, and dash dotted) indicate distinct regions of strong gradient as discussed in the text.

gradient images suggesting that there may be a link to the distinct gradients outlined by the dotted line.

\subsection{Anisotropy}

[34] The results from the inversion that incorporates azimuthal anisotropy (see section 3.1.1) are plotted in Figure 5, the same color scale as that for the isotropic inversion (Figure 3) is again used to illustrate the wave speed perturbations from the reference model ak135. At $100 \mathrm{~km}$ depth (Figure 5a) there is predominantly an eastwest direction of anisotropy within the continent. To the east of the line marking the strong gradient near the edge of the continent, the anisotropy is weaker and somewhat more varied in direction. At $150 \mathrm{~km}$ depth (Figure 5b) the fast direction of wave propagation is quite varied. In the western part of the model, in south Australia, strong east-west anisotropy is observed. Further north, the direction switches to a more north-south orientation, similar to plate motion. To the east of the dotted line the direction is more scattered, with no obvious pattern. By $200 \mathrm{~km}$ depth (Figure 5c), the east-west direction of anisotropy is only observed near the southern edge of central Australia. Throughout the rest of 

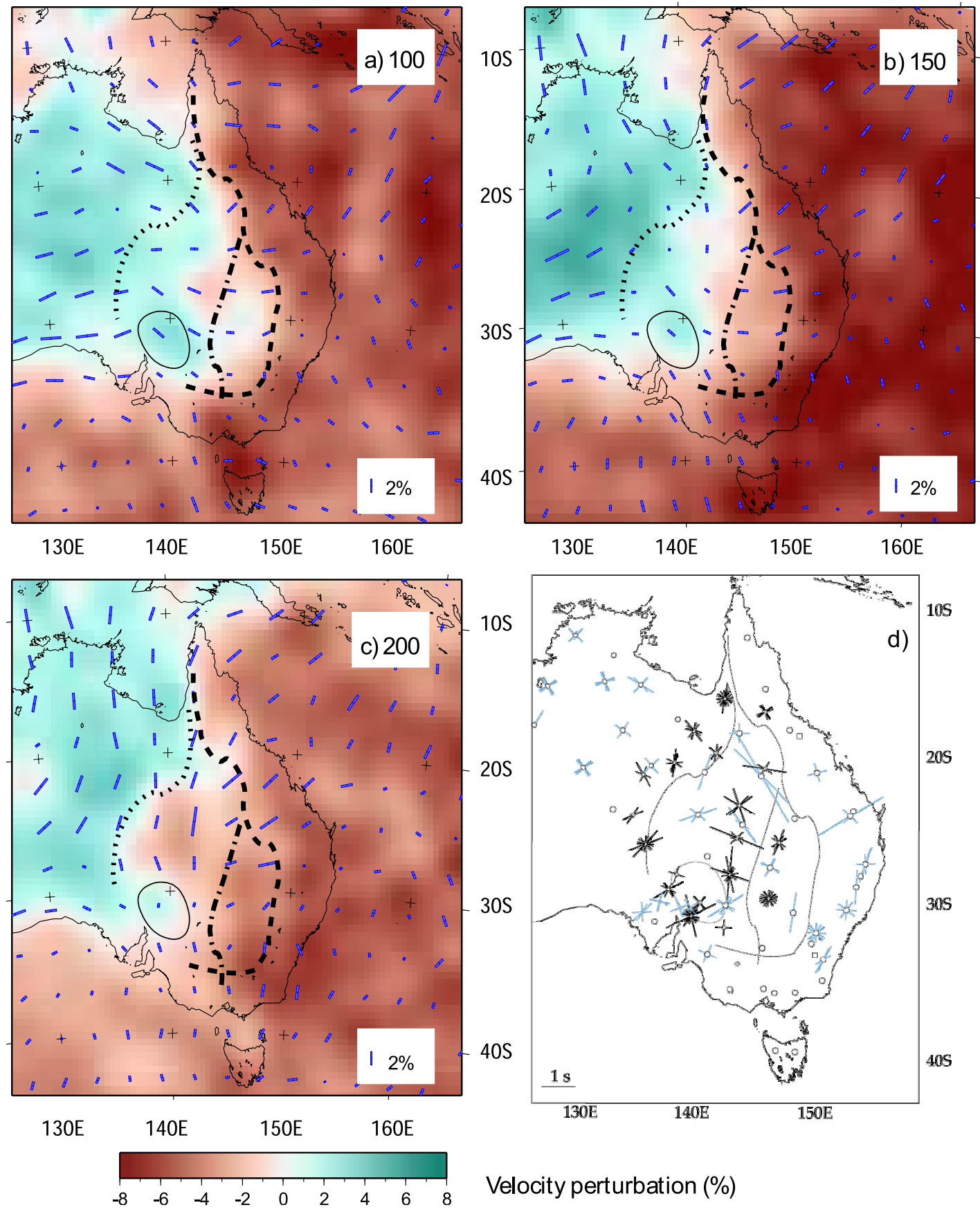

Figure 5. (a)-(c) Continental scale measurements of seismic anisotropy inferred from surface waves at 100-, 150-, and 200-km depth. The direction of the solid blue lines reflects the orientation of the fast polarization plane, and the length of the line is proportional to the magnitude of the anisotropy. (d) Shows the orientation of the fast polarization plane as inferred from shear-wave splitting measurements performed on core refracted shear waves. The length of each line is proportional to the delay, $\delta$ t, between the arrival of the fast and slow S waves. Null measurements are displayed as crosses, with lines orientated parallel and perpendicular to the direction of propagation.

central Australia the anisotropic direction has rotated through $90^{\circ}$, and we see strong and consistent north-south anisotropy west of $144^{\circ} \mathrm{E}$, close to the dash-dot line marking a region of strong shear wave speed gradients. Further east, the pattern of anisotropy is less consistent and smaller anomalies are observed.

[35] The smooth north-south pattern of anisotropy is compatible with a source from present-day deformation at 


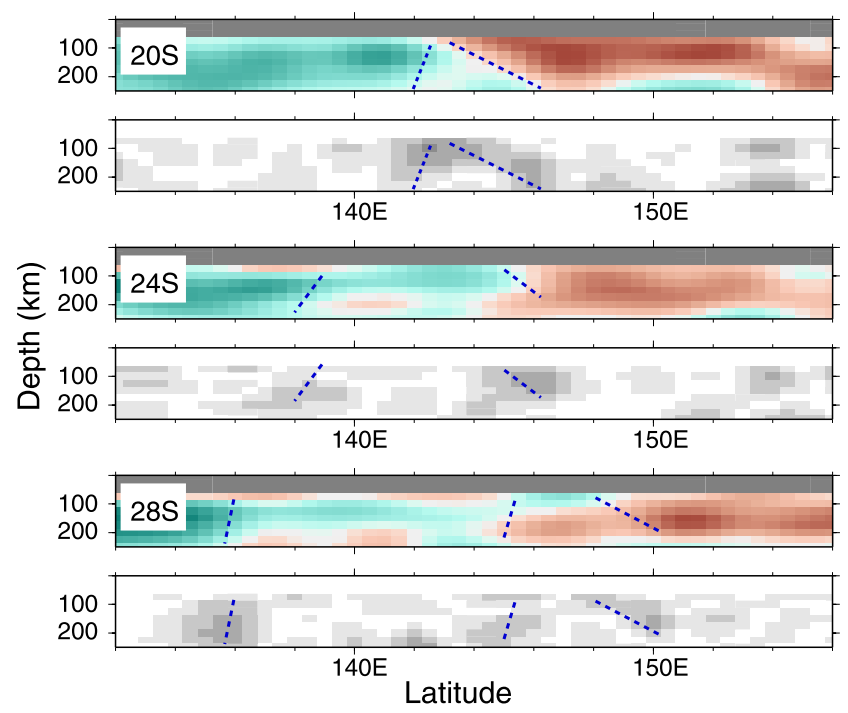

Figure 6. East-west cross sections at $20^{\circ}, 24^{\circ}$, and $28^{\circ}$ through the tomographic and gradient models. The same color scales as in Figures 3 and 4 are used. The dashed lines are chosen based on regions of strong gradients and then plotted on the tomographic cross sections.

the base of the lithosphere due to plate motion [Debayle et al., 2005]. The shallow anisotropy may relate to frozen deformation within the lithosphere. However, the east-west directions in central Australia are also consistent with the direction of maximum stress as predicted by models incorporating all plate boundary forces [Reynolds et al., 2003], suggesting that there may also be a component due to modern day deformation. These models are in general agreement with previous studies on azimuthal anisotropy in Australia that also suggest two layers of anisotropy [Simons et al., 2002; Debayle and Kennett, 2003], the finer details of the different studies still have significant variations.

[36] If we compare the pattern of velocity heterogeneity observed in the models that incorporate azimuthal anisotropy (Figures 5a, 5b, and 5c) with the isotropic inversion (Figures 3a, 3b, and 3c) we see that there is a similar overall pattern, although the inversions that incorporate anisotropy have smoother variations in velocity heterogeneity, which is particularly noticeable at $150 \mathrm{~km}$ depth (Figure 5b). Incorporating the terms for azimuthal anisotropy within the inversion procedure increases the number of unknowns (see equation 5) and, due to the trade off between increased heterogeneity and the amount of azimuthal anisotropy allowed, it is difficult to assess the appropriate damping and choice of final model. The additional anisotropic terms also require a very good distribution of crossing paths to obtain good resolution. For these reasons, we used the isotropic velocity models in the calculation of the horizontal gradients discussed in section 4.2.

[37] An alternative method of assessing seismic anisotropy is the computation of shear wave splitting measurements. Anisotropy measured on core refracted shear waves arriving at the seismological station with a nearly vertical incidence represents a vertically integrated effect from the core mantle boundary to the Earth surface. Despite the lack of vertical constraint, the lateral resolution of around $50 \mathrm{~km}$ obtained through body waves makes it a complementary analysis in conjunction with the study of anisotropy through surface waves.

[38] In Figure 5d we present a compilation of the results obtained by Heintz and Kennett [2005, 2006]. The figure contains data from the first three stages of the Skippy experiment, together with the analysis of two years of data recorded at stations deployed in the Tasmal experiment. Considering the full data set apparent isotropy is observed at many stations, confirming observations previously made by various authors at the Australian permanent seismological stations [Vinnik et al., 1992; Barruol and Hoffmann, 1999; Ozalaybey and Chen, 1999]. Significantly, the location of stations showing apparent isotropy is not constrained to any particular region of the continent, but are found on both sides of the various lines defining the regions of strong gradients in wave speeds.

[39] The Australian plate is a fast moving plate $(8 \mathrm{~cm} / \mathrm{yr})$, and therefore isotropy at the continental scale is hardly conceivable. It is rather the result of measurements performed under the assumption of a single layer of anisotropy, when two layers with perpendicular orientations of $\phi$ might be present [Heintz and Kennett, 2006]. This interpretation is in general agreement with the surface wave models showing evidence for two layers of anisotropy.

\subsection{Cross-Sections}

[40] Within eastern Australia the gradient maps suggest that there is not a gradual transition from the slow velocities at the eastern edge of the continent, to the fast velocities in central and western Australia. It appears that there may be a series of well defined transitions in velocity which can be described as steps in the structure of the lithosphere. Cross sections (Figure 6) through both the tomographic images and the gradient maps for three east-west lines, at 20,24 and $28^{\circ} \mathrm{S}$, give a clearer indication of the steps in lithospheric structure.

[41] In the northern cross-section, at $20^{\circ} \mathrm{S}$ there is a rapid transition from the thick zone of fast wave speeds to the slow velocities that appear to be typical of the eastern margin of the continent. The edge of the low-velocity structure is an east-dipping feature, however the strong gradients at $142^{\circ} \mathrm{E}$, make it unclear whether the apparently east-dipping fast velocities are a continuous feature related to the zone of thick lithosphere, or a separate region of higher wave speed.

[42] At $24^{\circ} \mathrm{S}$ the thickest lithosphere is seen to the west of $138^{\circ} \mathrm{E}$. Intermediate thicknesses and wave speeds occur between 138 and $146^{\circ} \mathrm{E}$. The change to the low velocities near the eastern edge of the continent is also marked by an east-dipping region of strong gradients. The east-dipping transition is obvious in the shallower part of the model. It is interesting to note that the tomographic cross-section indicates a west-dipping feature below $175 \mathrm{~km}$ depth. Although this feature does exist, the gradient cross-section shows that it has a smaller magnitude than the shallower east-dipping 


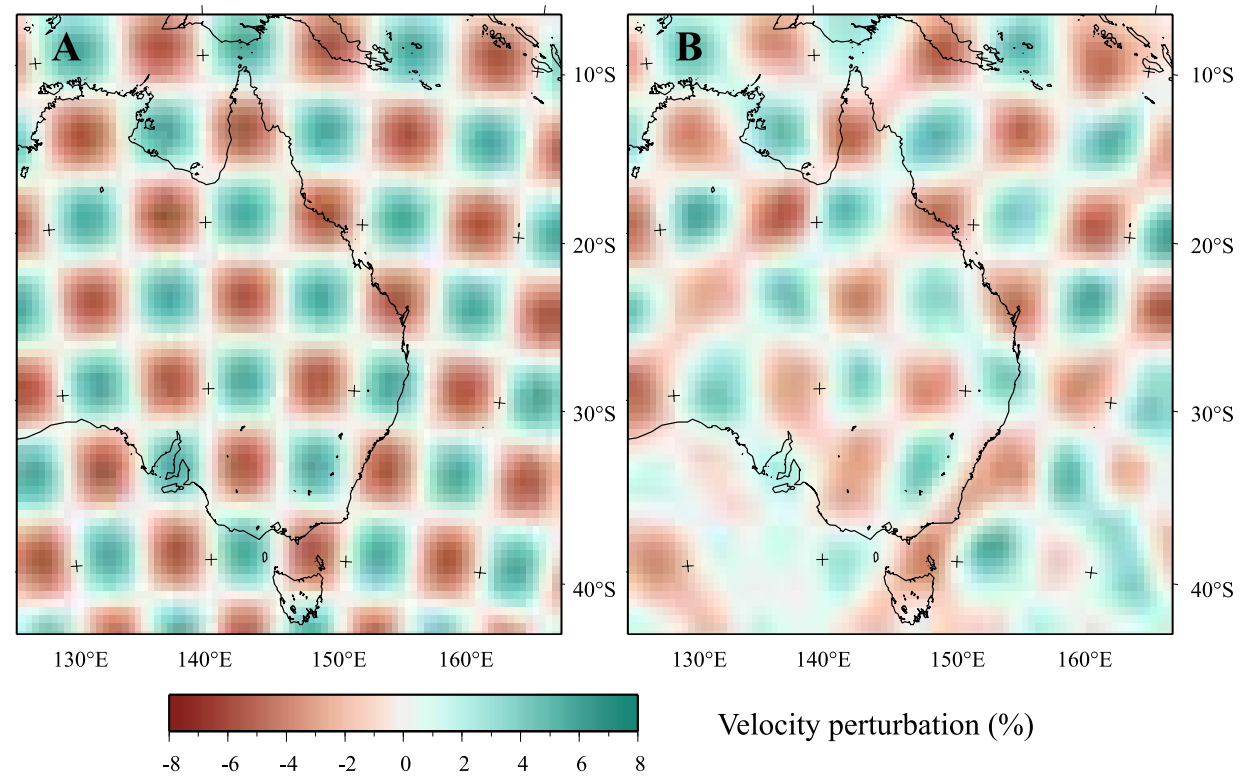

Figure 7. Synthetic test of the horizontal resolution for the tomographic inversion at $100 \mathrm{~km}$ depth. (a) Input structure: maximum perturbations of $\pm 5 \%$; (b) recovered structure with the same path coverage that is used to produce the tomographic models of the Australian region.

structure; in the tomographic cross-section the structure has been accentuated due to the change in color at this location.

[43] The southern cross-section, at $28^{\circ} \mathrm{S}$, indicates that the deep fast shear velocities are observed to the west of $136^{\circ} \mathrm{E}$. There is again a zone of intermediate depth lithosphere to about $146^{\circ} \mathrm{E}$. A narrow, shallow zone of fast velocities is observed between 146 and $148^{\circ} \mathrm{E}$, before reaching the east-dipping transition to very slow velocities at the edge of the continent.

\section{Reliability}

[44] We first illustrate the robustness of the tomographic image with a simple test, similar to a checkerboard. This style of test gives information on whether the path coverage (Figure 2) used in the inversion procedure is sufficient to recover a certain structure. The input model (Figure 7a) contains positive and negative velocity perturbations of $\pm 5 \%$. The regions of strong high and low velocity are about $4^{\circ}$ in size, and the transition occurs over an interval of less than $2^{\circ} .1 \mathrm{D}$ models are created from this input by averaging along the paths used in the inversion. As a means of simulating the limitations of the waveform inversion step, a component of noise has been added relative to the weighting used in the actual inversion. The resolution test is reconstructed for synthetic data at a depth of $100 \mathrm{~km}$. The path-averaged models are then employed to attempt to reconstruct the imposed wave speed structure.

[45] The resultant image from the tomographic inversion (Figure 7b), shows a good recovery of structure through continental Australia and the ocean to the east. The high and low anomalies are resolved, and the transition over a short scale length is well recovered. The test suggests that we are able to resolve features with horizontal scale lengths of greater than $300 \mathrm{~km}$. Although this particular test is for synthetic data at a depth of $100 \mathrm{~km}$, it is worth noting that as the depth of the tomographic image increases the horizontal resolution will decrease due to the greater uncertainty in the value of the path-average velocity. Care must also be taken in assuming that good recovery of synthetic structure from one checkerboard test implies real structure is resolved in the actual inversion. Lévêque et al. [1993] illustrated that simple checkerboard tests only indicate resolution for a particular scale of anomaly; using a specific path coverage it is possible to have good recovery of small-scale structure, while not able to resolve a larger-scale feature. Given the path coverage used in this tomographic model, and results of other synthetic tests not shown within this paper, this problem is not likely to be the case for the present data set.

[46] It is much more difficult to track the resolution in depth through the two-stage inversion process, as the smearing arises from the construction of each individual path-specific 1D model rather than in the calculation of the tomographic models. In the calculation of the path average 1D models we do not invert for the velocity structure in this region, and it remains fixed to the a priori 3SMAC model, therefore we do not compute tomographic models for the shallowest structure. For this reason, the top part of the models, at $50 \mathrm{~km}$ and above, is plotted in gray in the crosssections (Figure 6). Below $50 \mathrm{~km}$ depth, the vertical smoothing of the path-specific 1D models suggests there will be some leakage of information between adjacent depth intervals, but this is minimal when considering slices $50 \mathrm{~km}$ apart. Although each depth slice is calculated independently, through the careful choice of the damping (see equation 4), 


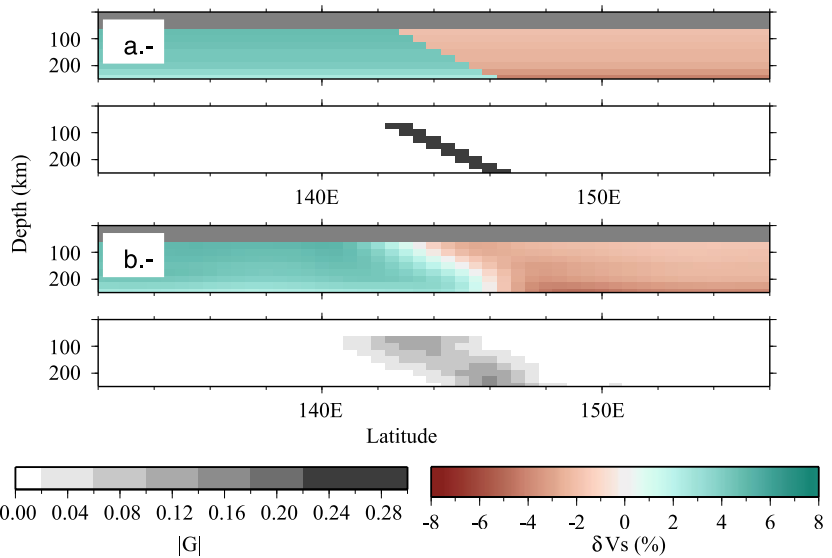

Figure 8. Synthetic test illustrating the recovery of a ramp structure when viewed in cross section, along an EW profile at $28^{\circ} \mathrm{S}$. (a) (top) Input structure, with velocities of $4.7 \mathrm{~km} / \mathrm{s}$ and $4.3 \mathrm{~km} / \mathrm{s}$ either side of the transition; (bottom) associated magnitude of the horizontal gradient (b) (top) recovered structure with the actual path coverage used in the tomographic models of the Australian region; (bottom) associated magnitude of the horizontal gradient for the recovered structure, note the smoother transition due to the B-spline parameterization.

we observe quite smooth variations in the velocity structure when cross sections are plotted.

[47] One of the main features that is observed in the cross sections of the tomographic models and gradient maps, is the rapid transition in shear wave speed that we describe as a step. In a second test we look at the impact that the path coverage, and particularly our choice of parameterization, will have on an actual jump in seismic velocities.

[48] Figure 8a shows a cross section through a model with a jump in seismic velocities, and the associated horizontal gradient for this input model. In the same method as for the previous test, synthetic data is calculated by averaging the velocities along the paths used in the inversion. In this test as we are focusing on the effect of the B-spline parameterization, we do not add any noise to the data. After independently inverting for each depth slice, the resultant cross sections through the tomographic model and for the horizontal gradients are shown in Figures 8 b.

[49] The results from the inversion indicate that we do recover the change from fast to slow wave speeds in the right location, however the nature of the transition has been changed. The zone of strongest gradient is now about $2^{\circ}$ wide, and small gradients are also observed further from the location of the true transition. The B-spline parameterization that is used imposes this style of smoothing on a true step feature. Other factors, such as the choice of the damping in the inversion, finite frequency effects caused by such a sharp transition, and also the actual noise in the real data will affect the recovery of the structure. However, this test suggests that it is likely that the gradients which are observed in the cross sections of the tomographic model (Figure 6) may be minimum estimates of the sharpness of any transition, due to the smoothing inherent in the B-spline parameterization.

\section{Discussion}

[50] As a guide to the structures discussed in the section 4, a cartoon schematic of eastern Australia is shown in Figure 9. The four lithospheric blocks have been defined with respect to coherent wave speed anomalies, with thicker lithosphere indicated where fast wave speeds extend to greater depths. The edges of the blocks have been delineated by strong horizontal gradients. The qualitative interpretation of lithospheric thickness is based on temperature being the dominant cause of wave speed variations. Other factors such as composition, water, partial melt and grain size that will also have an effect on the wave speed. Recent studies by Lee [2003] and Schutt and Lesher [2006] give wave speed perturbations of between $0.5-2 \%$ for variations in peridotite composition. In contrast, Goes et al. [2000] have shown that including the effects of anelasticity increases the influence of temperature on shear wave speed up to a maximum of $4 \%$ per $100^{\circ} \mathrm{C}$. Accounting for the combined influence of temperature and grain size Faul and Jackson [2005] showed that the large velocity differences between relatively young oceanic lithosphere and Archaean craton correspond to temperature differences of about $600^{\circ} \mathrm{C}$. Even if there are variations in composition within the lithosphere, it is likely that the large contrasts in shear wave speed remain most easily explained by variations in temperature, and thus lithospheric thickness.

[51] It is important to note that some of the features are exaggerated in the cartoon: the boundaries have been portrayed as sharp features, and we give the indication that each block has uniform structure. Due to the horizontal resolution of the tomographic images, it is not possible to define the sharpness of the transitions between the regions. The surface wave tomography also indicates that there is some variability of structure within each of our outlined blocks. Furthermore, the parameterization of the tomographic model will have an impact on the level of detail that can be resolved; models with smaller spacing of knot points will show more variations in wave speeds. From the tomographic models, the definition of the four blocks with similar wave speed structure cannot directly imply a coherent age or tectonic history within each particular block. However, combined with information from surface geology and geochemical studies we can make inferences on the features observed in our model.

\subsection{Western Transition}

[52] The westernmost region, block A, is associated with the thick lithosphere of the central shield. In the new model, in the north of Australia, the boundary is close to the eastern edge of the Mt Isa Block and runs in a north-south line, parallel to the Carpentaria conductivity anomaly [Lilley et al., 2003]. In this region the change from the fast wave speeds, associated with the shield region, to the slow wave speeds occurs very quickly. It is interesting that the transition in shear wave speeds occurs to the west of the 


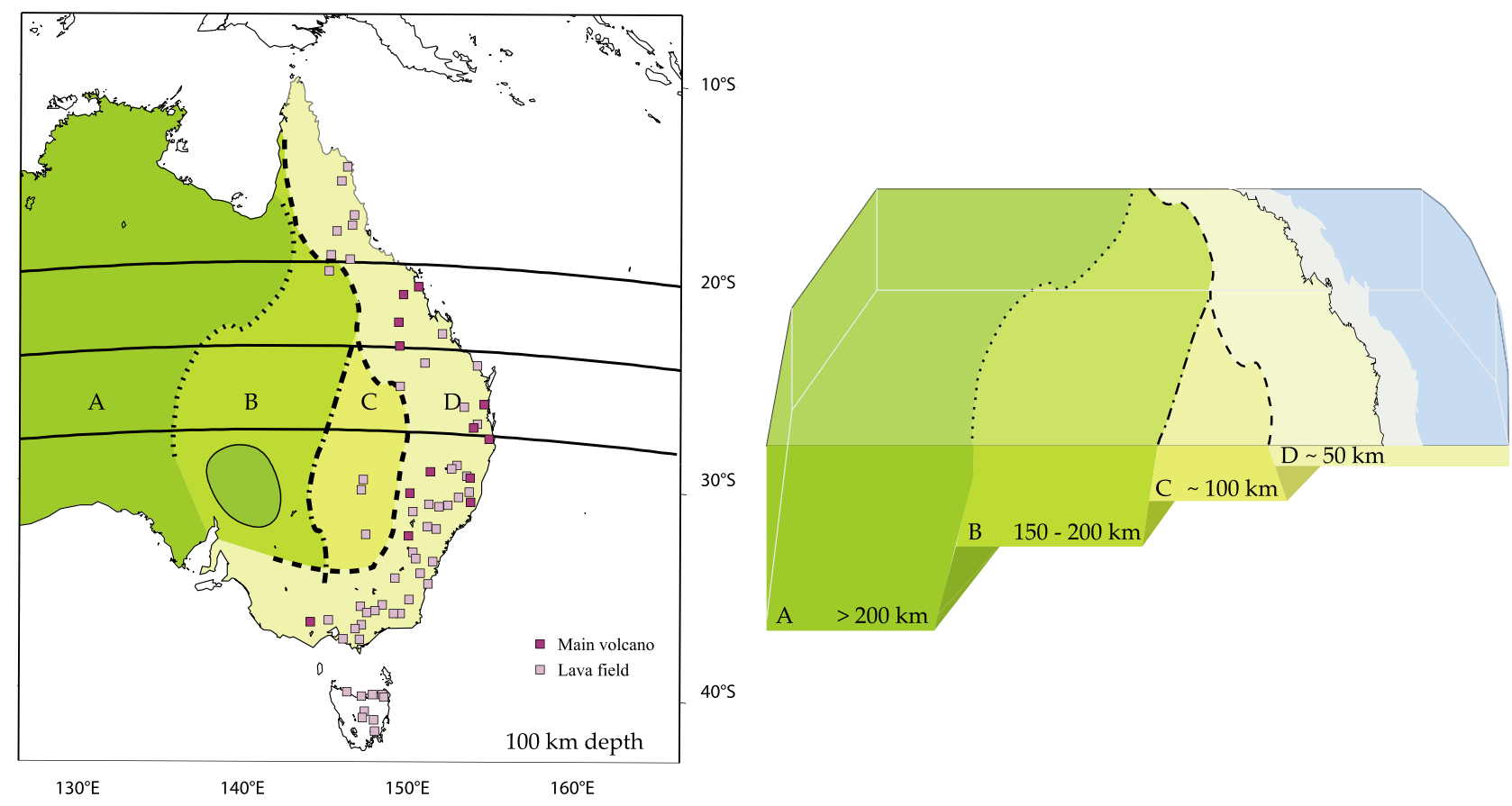

Figure 9. Cartoon schematic of the lithospheric structure beneath eastern Australia, based on the information from the tomography and gradient models. The lithospheric thicknesses are approximations based on the depth extent of positive (fast) velocity perturbations from the reference model ak135. The locations of recent volcanic activity [see Finn et al., 2005] are plotted as pink and purple squares.

Georgetown Inlier, rather than to the east where the Tasman Line has commonly been plotted. It is possible that the lithosphere beneath the Georgetown Inlier has been subject to the same influences that led to the slow velocities along the whole eastern margin of the continent (see section 6.3).

[53] South of the Mt Isa Block the lithospheric boundary is observed bending to the west, and then follows an approximately north-south direction at a longitude of about $136^{\circ} \mathrm{E}$. In this region the boundary in the shear wave speeds is most obvious at $150-250 \mathrm{~km}$ depth, and the gradient map at $100 \mathrm{~km}$ (Figure 4) does not illustrate this feature. The position of the boundary in this region follows a similar pattern to the proposed locations of the Tasman Line as defined from the magnetic anomalies and outcrop. It is difficult to find a causal explanation for the correlation between the trend in magnetic anomalies - in the crust, and the lithospheric boundary highlighted by strong gradientsat $200 \mathrm{~km}$ depth in the mantle.

[54] To the south of the section at $28^{\circ} \mathrm{S}$, the seismic structure is more complex, and there is a less obvious transition from the region of deep lithosphere to the region of shallower lithosphere. Beneath the Gawler Craton low velocities are seen in the upper part of the model, while by 200-250 km depth there are faster velocities. These fast velocities appear to link with a NW-SE trending zone of high wave speed (Figure 3d). It is unclear whether this is evidence for a deep continental lithospheric root. A distinct feature in the tomographic models and gradient maps is the fast wave speeds occurring to at least $200 \mathrm{~km}$ depth in the vicinity of the Curnamona Block. The separation of the lithospheric structure beneath this region from the thick zone of fast wave speeds to the west could be a result of the rearrangement of the Australian continent at approximately $1.5 \mathrm{Ga}$, when the Curnamona Block is thought to have rotated away from its original location adjacent to the Mt Isa Block [Giles et al., 2004]. If this is the case, we are likely to be observing the retention of ancient lithospheric structure beneath these crustal blocks.

[55] Betts et al. [2002] note that there is a possibility that much of the lithosphere beneath Proterozoic Australia may have been Archaean in age. Although both the Mt Isa Block and Curnamona Blocks have a distinct history of Proterozoic evolution, the indication of Archaean material from geochemical studies [e.g., Griffin et al., 2006; Nutman and Ehlers, 1998] in both regions and the deep, fast shear wave speeds apparent in the present model, lead us to suggest that this western transition may be the signature of the edge of an Archaean-Early Proterozoic core to the Australian continent. It is noticeable that the inclusion of the new data from the Tasmal experiment gives a somewhat different shape and location to the edge of the region of thickest lithosphere when compared in plan view to the previous results of Kennett et al. [2004].

\subsection{Central Transitions}

[56] The middle two lithospheric blocks are the hardest to categorize, as they are beneath regions with very limited outcrop. The geochemical evidence clearly suggests that there is Proterozoic lithospheric mantle to the east of the proposed Tasman Line in the southern part of the continent 
[McBride et al., 1996; Handler and Bennett, 2001]. The local teleseismic tomography models of Graeber et al. [2002] and Rawlinson et al. [2006] also indicate changes from fast to slow wave speeds which may represent this change from Proterozoic to Phanerozoic basement. While the surface wave tomography does not have the lateral resolution of the teleseismic studies, it is possible that the zone of strong gradients on the eastern edge of block B is representative of this change from old to young basement.

[57] Within block B the tomographic images indicate fast wave speeds, relative to the reference model ak135 to a depth of $150-175 \mathrm{~km}$. Fast shear velocities, observed to this depth, are compatible with the idea that we are imaging Proterozoic lithosphere. Global studies on the average thickness of lithosphere of different ages suggest a depth of approximately $150 \mathrm{~km}$ is common for mid-late Proterozoic Cratons [Polet and Anderson, 1995; Artemieva and Mooney, 2001]. While the edge of block B has been defined by the horizontal gradients, it is noticeable that at $200 \mathrm{~km}$ depth the strong NS azimuthal anisotropy, parallel to plate motion, is only observed within blocks A and B (Figure 5). If this azimuthal anisotropy is caused by the deformation at the base of the lithosphere due to the rapid plate motion [Debayle et al., 2005], it is not surprising that we observe the strongest NS anisotropy at $200 \mathrm{~km}$ depth in regions with lithospheric thicknesses in the order of $150-200 \mathrm{~km}$.

[58] Further north beneath the Thomson Orogen we see a similar wave speed structure. Unfortunately, there is no outcrop or geochemical data to give additional constraints on the nature of the lithosphere in this region. However, the seismic data, and inferences from the gradient mapping suggest the whole block may be underlain by Proterozoic lithosphere. From the surface wave tomography alone it is not possible to indicate whether this block may indicate a possible edge of Rodinia further east than the Tasman Line (as suggested by Direen and Crawford [2003]) or simply Proterozoic continental lithosphere that may have been attached during the Phanerozoic accretionary events in eastern Australia [Betts et al., 2002].

[59] In our conceptual model, between $24^{\circ}-34^{\circ} \mathrm{S}$, to the east of the Proterozoic region, is a small block of lithosphere (block C). Beneath this zone, fast velocities are observed to around $100 \mathrm{~km}$ in depth. The thinner lithosphere in comparison to the blocks to the west, and lack of geochemical evidence relating this region to Precambrian basement, suggests that this may be a region of Phanerozoic lithosphere. This region also contrasts with the eastern edge of the continent, where we observe very low wave speeds in the shallowest depths of the model.

\subsection{Eastern Transition}

[60] Close to the eastern margin of the Australian continent there is a continuous region of strong horizontal wave speed gradients in the shallowest part of the tomographic models (Figures $4 \mathrm{a}$ and $4 \mathrm{~b}$ ). At $100 \mathrm{~km}$ depth very slow velocities are seen significantly inland of the continentocean boundary (Figures $3 \mathrm{a}$ and $3 \mathrm{~b}$ ), and the change from these slow wave speeds to faster wave speeds to the west creates the strong gradient. Despite a lack of seismological stations very close to the eastern coast the resolution test (Figure 7) indicates that structures on the margin are well resolved. The path coverage is very good, and the low wave speeds are not a result of smearing of suboceanic mantle velocities inland.

[61] Before further discussing this region of inland low velocities (Figure 9, block D) it is worth commenting on the velocities observed beneath the Tasman and Coral Seas to the east of Australia. Sea floor spreading, which began in the south and propagated northward, gives ages of the oceanic crust from about 80 and 50 Ma [Gaina et al., 1998]. In Figure 3a there is a NS trending region (approx $155^{\circ} \mathrm{E}$, and $17-27^{\circ} \mathrm{N}$ ) with slightly faster velocities than the surroundings. This region correlates well with the northward extent of oceanic crust which formed about $60 \mathrm{Ma}$. Based on simple models of lithospheric cooling we would expect lithospheric thicknesses of about $80-90 \mathrm{~km}$ beneath ocean of this age.

[62] From tomography alone, the cause of the low velocities beneath the continent and strong wave speed gradient is difficult to ascertain; however, it appears that this largescale feature may have a role in the present geology of the eastern margin and is therefore worth further discussion. There is a very strong correlation with the location of recent igneous activity and the slow wave speeds on the eastern margin (Figure 9). Furthermore, this eastern block also correlates with the position of the Eastern Highlands (Figure 1b). If the low velocities are a result of high temperatures, this could be evidence of thermal buoyancy as a present day factor for the high elevations on the eastern edge of the continent. Using the extent of fast wave speeds as the basis for defining a thickness of the lithosphere is not directly possible as we never see positive wave speed perturbations in this region. Given that we see slightly slower velocities beneath the continent than beneath the northern Tasman Sea, where estimates of lithospheric thickness from the age of the crust are around $80-90 \mathrm{~km}$, on Figure 9 we have suggested a thickness of approximately $50 \mathrm{~km}$. This may be an underestimate, but is used to highlight the anomalous nature of the region.

[63] A thin lithosphere predicted from the tomography is in agreement with indications of a thin elastic lithosphere: at a large scale, from measurements of gravity and topography [Zuber et al., 1989; Swain and Kirby, 2006]; and more locally, from modeling of low temperature thermochronological data [Braun and van der Beek, 2004]. Zuber et al. [1989] suggested that the low-elastic thickness $(15-30 \mathrm{~km})$, comparable to the east African rift zone, could be caused by the prolonged history of thermal and tectonic activity in the Phanerozoic relating to offshore sea floor spreading and volcanism. The correlation with recent volcanism (Figure 9) certainly suggests that there will be a different thermal profile to regions away from the volcanic activity.

[64] If the volcanism has been caused by a mantle plume, then it is possible that the passage of the continent over the plume head could have resulted in the thinning of the continental lithosphere, which would account for the low uppermost mantle velocities observed today. Even if the volume of extrusive volcanism is not significant enough to 
have caused a major thinning of the lithosphere, there may still be the imprint of the thermal upwelling within the tomographic models. Sutherland [2003] noted that the bends ("boomerangs") in the hotspot tracks (Figure 1b) did not match any pronounced mantle features from the model of Simons et al. [1999]. The new models presented here indicate that a zone of higher wave speeds extending further east, with a sharp edge to a depth of about $100-150 \mathrm{~km}$, may have affected the location of the volcanism. If this edge feature was in place prior to the volcanism it is possible that any mantle plume may have been deflected around the region of thicker lithosphere, causing the volcanism to occur along a bent path. This may be an example of where a step in lithospheric structure is playing an important role in the subsequent tectonic evolution of a region.

[65] A pre-existing lithospheric feature may have also been a more direct cause for the volcanism. King and Ritsema [2000] suggest that African intraplate volcanism may be caused by small-scale edge driven convection at the boundary of thick cratonic lithosphere. Recently, edge driven convection has been advocated as a potential cause of the Newer Volcanic Province in South Australia [Demidjuk et al., 2007]. In southern Australia the high angle between the lithospheric edge, and the rapid northward plate motion may help stimulate the upwelling. Whether this mechanism will be as efficient on the eastern margin, where the lithospheric edge is predominantly parallel to the plate motion, remains to be answered.

[66] If the step in lithospheric thickness was a pre-existing feature, one possibility is that it formed during the rifting of the Tasman Sea. Simple models of lithospheric thinning and subsequent thermal relaxation suggest that there would not be a significant heat flow anomaly remaining due to the rifting (D. Müller, personal communication, 2007). However, if asymmetric passive margin formation does lead to removal of continental lithosphere [Lister and Etheridge, 1989] then we have a potential mechanism for establishing a step in lithospheric thickness. From the tomography alone it is impossible to tell if the lithospheric-scale boundary was already in place prior to rifting and volcanism or if it is simply a recent feature. In the north of Australia, if the Georgetown Inlier had previously been underlain with a deep lithospheric root, then a substantial thickness of lithosphere must have been removed to explain the low velocities observed in the present tomographic model. Future work investigating the thermal structure of the eastern margin of Australia should lead to a better understanding of this region of slow wave speeds.

\subsection{Lithospheric Steps: Comparison With the Trans-European Suture Zone}

[67] The concept of steps in lithospheric structure is not a new one. In northern Europe the Trans-European Suture Zone (TESZ) is the boundary between the ancient Precambrian Baltic shield region and younger NeoproterozoicPalaeozoic terranes of western Europe [see, e.g., Pharaoh, 1999, for a review]. The Tornquist Zone, at the western extent of the TESZ, was studied using temporary deployments of seismometers in southern Sweden, Denmark and northern Germany [Gregersen et al., 2002]. Results from body wave tomography [Shomali et al., 2002], surface wave dispersion [Cotte et al., 2002] and seismic anisotropy [Plomerová et al., 2002; Babuška and Plomerová, 2004] suggest two sharp transitions delineating boundaries between separate lithospheric blocks.

[68] The surface wave dispersion study by Cotte et al. [2002] suggests that there is a major discontinuity extending to a depth of $200 \mathrm{~km}$ at the Sorgenfrei-Tornquist Zone, separating the Baltic shield from a block of Danish lithosphere. The second discontinuity occurs at the southern edge of the Danish block, and is observed to depths of about $150 \mathrm{~km}$. In comparison to the Baltic Shield and the Phanerozoic Terranes of northern Germany, the Danish block appears to have a lithosphere of intermediate thickness [Cotte et al., 2002]. It may represent an allochtonous block caught between the collision of northern Europe and Baltica [Babuška and Plomerová, 2004].

[69] When compared to the TESZ, the tomographic models and gradient maps of Australia suggest a similar style of lithospheric steps: older, thicker lithosphere to the west, and younger, thinner lithosphere in the east. However, in contrast to the work on the anisotropy in the region of the TESZ [Plomerová et al., 2002; Babuška and Plomerová, 2004], the seismic anisotropy for Australia does not give a simple result. From surface waves, there appear to be some changes in the pattern of azimuthal anisotropy that can be related to the different blocks, particularly the strong NS anisotropy at depths of $200 \mathrm{~km}$ beneath the two blocks of thickest lithosphere, however in general the patterns are more complicated. Furthermore, the shear wave splitting measurements indicate apparent isotropy, probably caused by two layers with a perpendicular orientation of $\phi[$ Heintz and Kennett, 2006], throughout most of the region, with no distinct differences in character of the results between the different blocks.

\subsection{Conclusions}

[70] A detailed investigation of the shear wave speed structure in eastern Australia reveals that there are a series of steps in lithospheric thickness. The transition from the thickest coherent lithosphere of the central shield region, has a more complex pattern than previously observed in the work of Kennett et al. [2004]. In northern Australia a very rapid change in shear wave speed, from fast velocities relating to the shield region to slow velocities on the eastern margin is observed. This lithospheric boundary occurs close to the Carpentaria Conductivity Anomaly, west of the Georgetown Inlier. Further south, the transition from the fast velocities associated with the thick lithosphere of the shield to the very slow velocities related to the eastern margin occurs as a series of steps, rather than a single jump in thickness or a smooth transition. The intermediate steps appear to be related to changes in age of the underlying lithosphere. A distinct band of low velocities is observed on the eastern margin of Australia, beneath the highest topography of the Australian continent. Nearly all the recent volcanism in eastern Australia is found in this region. The western edge of this low-velocity zone is delineated by 
a strong horizontal gradient in wave speed at a relatively consistent distance of about 300 kilometers inland of the coast, suggesting a step in lithospheric thickness. If this step was in place prior to the volcanism it may have acted as a physical barrier; with volcanism occurring beneath the thinner lithosphere to the east.

[71] Acknowledgments. We'd like to thank everyone at the Research School of Earth Sciences, Australian National University, who has been involved in the many fieldwork deployments in Australia, a particular mention goes to both Steve Sirotjuk and Armando Arcidiaco. Thanks to Dietmar Müller for a helpful review and further discussion and for providing information on location of volcanics in east Australia. The constructive comments from Scott King, three other anonymous reviewers, and the associate editor have also helped to improve the manuscript. This study was partly supported by a Grant in Aid for Scientific Research (No. 17740283) to KY from the Ministry of Education, Culture, Sports, Science, and Technology of Japan.

\section{References}

Artemieva, I. M., and W. D. Mooney (2001), Thermal thickness and evolution of Precambrian lithosphere, J. Geophys. Res., 106, 16,387-16,414

Babuška, V., and J. Plomerová (2004), The SorgenfreiTornquist Zone as the mantle edge of Baltica lithosphere: New evidence from three-dimensional seismic anisotropy, Terra Nova, 16, 243-249.

Barrell, J. (1914), The strength of the Earth's crust, J. Geol., 22, 425-433.

Barruol, G., and R. Hoffmann (1999), Upper mantle anisotropy beneath Geoscope stations, J. Geophys. Res., 104, 10,757-10,773.

Betts, P. G., D. Giles, G. S. Lister, and L. R. Frick (2002), Evolution of the Australian lithosphere, Aust. J. Earth Sci., 49, 661-695.

Boger, S. D., and D. Hansen (2004), Metamorphic evolution of the Georgetown Inlier, northeast Queensland, Australia; evidence for an accreted Palaeoproterozoic terrane?, J. Metamorph. Geol., 22, 511-527.

Braun, J., and P. van der Beek (2004), Evolution of passive margin escarpments: What can we learn from low-temperature thermochronology, J. Geophys. Res., 109, F04009, doi:10.1029/2004JF000147.

Cara, M., and J. J. Lévêque (1987), Waveform inversion using secondary observables, Geophys. Res. Lett., 14, 1046-1049.

Cayley, R. A., D. H. Taylor, A. H. M. VandenBerg, and D. H. Moore (2002), Proterozoic_-Early Palaeozoic rocks and the Tyennan Orogeny in central Victoria: The Selwyn Block and its tectonic implications, Aust. J. Earth Sci., 49, 225-254.

Cleary, J. (1967), $P$ times to Australian stations from nuclear explosions, Bull. Seismol. Soc. Am., 57, $773-781$.

Cotte, N., H. A. Pedersen, and TOR Working Group (2002), Sharp contrast in lithospheric structure across the Sorgenfrei-Tornquist Zone as inferred by Rayleigh wave analysis of TOR 1 project data, Tectonophysics, 360, 75-88.

Debayle, E. (1999), $S V$-wave azimuthal anisotropy in the Australian upper mantle: Preliminary results from automated Rayleigh waveform inversion, Geophys. J. Int., 137, 747-754.

Debayle, E., and B. L. N. Kennett (2003), Surface wave studies of the Australasian region, in The Evolution and Dynamics of the Australian Plate, edited by R. Hillis and D. Müller, pp. 25-40, Geol. Societies of Australia and Am, special paper 372.

Debayle, E., B. L. N. Kennett, and K. Priestley (2005), Global azimuthal seismic anisotropy: The unique plate-motion of Australia, Nature, 433, 509-512.

Demidjuk, Z., S. Turner, M. Sandiford, R. George, J. Foden, and M. Etheridge (2007), U-series isotope and geodynamic constraints on mantle melting processes beneath the Newer Volcanic Province in South Australia, Earth Planet. Sci. Lett., 261, $517-533$.

Direen, N. G., and A. J. Crawford (2003), The Tasman Line: Where is it, and is it Australia's Rodinian breakup boundary?, Aust. J. Earth Sci., 50, $491-$ 502.

Dziewonski, A. M., and D. L. Anderson (1981), Preliminary reference earth model, Phys. Earth Planet. Inter., 25, 297-356.
Faul, U. H., and I. Jackson (2005), Seismic signatures of temperature variations in the upper mantle, Earth Planet. Sci. Lett., 234, 119-134.

Finn, C. A., R. D. Müller, and K. S. Panter (2005), A Cenozoic diffuse alkaline magmatic province (DAMP) in the southwest Pacific without rift or plume origin, Geochem. Geophys. Geosyst., 6 Q02005, doi:10.1029/2004GC000723.

Fishwick, S. (2006), Gradient maps: A tool in the interpretation of tomographic images, Phys. Earth Planet. Inter., 156, 152-157.

Fishwick, S., B. L. N. Kennett, and A. M. Reading (2005), Contrasts in lithospheric structure within the Australian Craton-Insights from surface wave tomography, Earth Planet. Sci. Lett., 231, $163-$ 176.

Foster, D. A., and D. R. Gray (2000), Evolution and structure of the Lachlan Fold Belt (Orogen) of eastern Australia, Annu. Rev. Earth Planet. Sci., 28 , $47-80$

Gaina, C., R. D. Müller, J. Y. Royer, J. M. Stock, J. Hardebeck, and P. Symonds (1998), The tectonic history of the Tasman Sea: A puzzle with thirteen pieces, J. Geophys. Res., 103, 12,413-12,433.

Giles, D., P. G. Betts, and G. S. Lister (2002), Far-field continental backarc setting for $1.80-1.67$ ga basins of northern Australia, Geology, 30, 823-826.

Giles, D., P. G. Betts, and G. S. Lister (2004), 1.8 1.5-Ga links between the North and South Australian Cratons and the Early-Middle Proterozoic configuration of Australia, Tectonophysics, 380, 27-41.

Glen, R. A. (2005), The Tasmanides of eastern Australia, in Terrane Processes at the Margins of Gondwana, vol. 246, edited by A. P. M. Vaughan et al., pp. 23-96, Geol. Soc., London.

Goes, S., F. Cammarano, and U. Hansen (2000), Shallow mantle temperatures under Europe from $P$ and $S$ wave tomography, J. Geophys. Res., 105 , $11,153-11,169$

Goes, S., F. Simons, and K. Yoshizawa (2005), Seismic constraints on the temperature of the Australian uppermost mantle, Earth Planet. Sci. Lett., 236 $227-237$.

Goncz, J. H., and J. R. Cleary (1976), Variations in the structure of the upper mantle beneath Australia, from Rayleigh wave observations, Geophys. J. R Astron. Soc., 44, 507-516.

Graeber, F. M., G. A. Houseman, and S. A. Greenhalgh (2002), Regional teleseismic tomography of the western Lachlan Orogen and the Newer Volcanic Province, southeast Australia, Geophys. J. Int., 149, 249-266

Gray, D. R., and D. A. Foster (2004), Tectonic evolution of the Lachlan Orogen, southeast Australia: Historical review, data synthesis and modern perspectives, Aust. J. Earth Sci., 51, 773-817.

Gregersen, S., P. Voss, and TOR Working Group (2002), Summary of project TOR: Delineation of stepwise, sharp, deep lithosphere transition across Germany-Denmark-Sweden, Tectonophysics, 360, $61-73$

Griffin, W. L., E. A. Belousova, S. G. Walters, and S. Y. O'Reilly (2006), Archaean and Proterozoic crusta evolution in the Eastern succession of the Mt Is district, Australia: $\mathrm{U}-\mathrm{Pb}$ and $\mathrm{Hf}$-isotope studies of detrital zircons, Aust. J. Earth Sci., 53, 125-149.

Gunn, P. J., P. Milligan, T. Mackey, S. Liu, A. Murray, D. Maidment, and R. Haren (1997), Geophysical mapping using the national airborne and gravity datasets; an example focusing on Broken Hill, AGSO J. Aust. Geol. Geophys., 17, 127-136.

Handler, M. R., and V. C. Bennett (2001), Constraining continental structure by integrating Os isotopic ages of lithospheric mantle with geophysical and crusta data: An example from southeastern Australia, Tectonics, 20, 177-188.

Heintz, M., and B. L. N. Kennett (2005), Seismic anisotropy beneath the Australian continent inferred from shear-wave splitting analysis, Earth Planet. Sci. Lett., 236, 106-119.

Heintz, M., and B. L. N. Kennett (2006), The apparently isotropic Australian upper mantle, Geophys. Res. Lett., 33, L15319, doi:10.1029/2006GL026401.

Hill, D. (1951), Geology, in Handbook of Queensland, edited by G. Mack, Australian Assoc. for the Advancement of Sci., Brisbane.

Jaques, A. L., and P. R. Milligan (2004), Patterns and controls on the distribution of diamondiferous intrusions in Australia, Lithos, 77, 783-802.

Johnson, R. W. (1989), Intraplate Volcanism in Eastern Australia and New Zealand, Cambridge Univ. Press, New York

Kennett, B. L. N., E. R. Engdahl, and R. Buland (1995), Constraints on seismic velocities in the Earth from travel times, Geophys. J. Int., 122, $108-124$

Kennett, B. L. N., S. Fishwick, A. M. Reading, and N. Rawlinson (2004), Contrasts in mantle structure beneath Australia-Relation to Tasman Lines, Aust. $J$ Earth Sci., 51, 563-569.

King, S. D., and J. Ritsema (2000), African hot spot volcanism: Small-scale convection in the upper mantle beneath cratons, Science, 290, 1137-1140.

Lambeck, K., and R. Stephenson (1986), The postPalaeozoic uplift history of southeastern Australia, Aust. J. Earth Sci., 33, 253-270.

Lee, C.-T. A. (2003), Compositional variation of density and seismic velocities in natural peridotites at STP conditions; implications for seismic imaging of compositional heterogeneities in the upper mantle, J. Geophys. Res., 108(B9), 2441, doi:10.1029/ 2003JB002413.

Lévêque, J. J., L. Rivera, and G. Wittlinger (1993), On the use of the checker-board test to assess the resolution of tomographic inversions, Geophys. J. Int., 115, 313-318

Lévêque, J. J., E. Debayle, and V. Maupin (1998), Anisotropy in the Indian Ocean upper mantle from Rayleigh- and Love-waveform inversion, Geophys. J. Int., 133, 529-540.

Lilley, F. E. M., L. J. Wang, F. H. Chamalaun, and I. J. Ferguson (2003), Carpenteria Electrical Conductivity Anomaly, Queensland, as a major structure in the Australian Plate, in The Evolution and Dynamics of the Australian Plate, edited by R. Hillis and D. Müller, pp. 141-156, Geol. Societies of Australia and Am, special paper 372

Lister, G. S., and M. A. Etheridge (1989), Detachment models for uplift and volcanism in the Eastern 
Highlands, and their application to the origin of passive margin mountains, in Intraplate Volcanism in Eastern Australia and New Zealand, edited by R. W. Johnson, pp. 297-312, Cambridge Univ. Press, New York.

McBride, J. S., D. D. Lambert, A. Greig, and I. A. Nicholls (1996), Multistage evolution of Australian subcontinental mantle: Re-Os isotopic constraint from Victorian mantle xenoliths, Geology, 24, $631-634$.

Menke, W. (1989), Geophysical Data Analysis: Discrete Inverse Theory, Academic Press, San Diego.

Montagner, J.-P., and H.-C. Nataf (1986), A simple method for inverting the azimuthal anisotropy of surface waves, J. Geophys. Res., 91, 511-520.

Nataf, H.-C., and Y. Ricard (1996), 3SMAC: An a priori tomographic model of the upper mantle based on geophysical modeling, Phys. Earth Planet. Inter., 95, 101-122.

Nutman, A. P., and K. Ehlers (1998), Archaean crust near Broken Hill, Aust. J. Earth Sci., 45, 687-694.

O'Sullivan, P. B., D. X. Belton, and M. Orr (2000), Post-orogenic thermotectonic history of the Mount Buffalo region, Lachlan Fold Belt, Australia: Evidence for Mesozoic to Cenozoic wrench-fault reactivation?, Tectonophysics, 317, 1-26.

Ozalaybey, S., and W. P. Chen (1999), Frequencydependent analysis of SKS/SKKS waveforms observed in Australia; evidence for null birefringence, Phys. Earth Planet. Inter., 114, 197-210.

Paige, C. C., and M. A. Saunders (1982), LSQR: An algorithm for sparse linear equations and sparse least squares, ACM Trans. Math. Softw., 8, 43-71.

Persano, C., F. M. Stuart, P. Bishop, and T. J. Dempster (2005), Mdeciphering continental breakup in eastern Australia using low-temperature thermochronometers, J. Geophys. Res., 110, B12405, doi:10.1029/2004JB003325.

Pharaoh, T. C. (1999), Palaeozoic terranes and their lithospheric boundaries within the Trans-European Suture Zone (TESZ): A review, Tectonophysics, $314,17-41$.

Plomerová, J., V. Babuška, L. Vecsey, D. Kouba, and TOR Working Group (2002), Seismic anisotropy of the lithosphere around the Trans-European Suture Zone (TESZ) based on teleseismic body-wave data of the TOR experiment., Tectonophysics, 360, 89114

Polet, J., and D. L. Anderson (1995), Depth extent of cratons as inferred from tomographic studies, Geology, 23, 205-208

Priestley, K., and D. McKenzie (2006), The thermal structure of the lithosphere from shear wave velocities, Earth Planet. Sci. Lett., 244, 285-301.

Rawlinson, N., B. L. N. Kennett, and M. Heintz (2006), Insights into the structure of the upper mantle be- neath the murray basin from 3-D teleseismic tomography, Aust. J. Earth Sci., 53, 595-604.

Reynolds, S. D., D. D. Coblentz, and R. R. Hillis (2003), Influences of plate-boundary forces on the regional intraplate stress field of continental Australia, in The Evolution and Dynamics of the Australian Plate, edited by R. Hillis and D. Müller, pp. 59-70, Geol. Societies of Australia and Am, special paper 372

Scheibner, E., and J. J. Veevers (2000), 19. Tasman Fold Belt System, in Billion-Year Earth History of Australia and Neighbours in Gondwanaland, edited by J. J. Veevers, pp. 154-234, GEMOC Press, Sydney.

Schutt, D. L., and C. E. Lesher (2006), Effects of melt depletion on the density and seismic velocity of garnet and spinel lherzolite, J. Geophys. Res., 111 B05401, doi:10.1029/2003JB002950.

Shaw, R. D., P. Wellman, P. J. Gunn, A. J. Whitaker, C. Tarlowski, and M. P. Morse (1996), Guide to using the Australian crustal elements map, Australian Geological Survey Organisation Record, 1996/30.

Shomali, Z. H., R. G. Roberts, and TOR Working Group (2002), Non-linear body wave teleseismic tomography along the TOR array, Geophys. J. Int. $148,562-574$.

Simons, F. J., and R. D. van der Hilst (2002), Age-dependent seismic thickness and mechanical strength of the Australian lithosphere, Geophys. Res. Lett., 29(11), 1529, doi:10.1029/2002GL014962.

Simons, F. J., A. Zielhuis, and R. D. van der Hilst (1999), The deep structure of the Australian continent from surface wave tomography, Lithos, 48 , $17-43$.

Simons, F. J., R. D. van der Hilst, J.-P. Montagner, and A. Zielhuis (2002), Multimode Rayleigh wave in version for heterogeneity and azimuthal anisotropy of the Australian upper mantle, Geophys. J. Int. $151,738-754$.

Sutherland, F. L. (2003), "Boomerang" migratory intraplate Cenozoic volcanism, eastern Australian rift margins and the Indian-Pacific mantle boundary, in The Evolution and Dynamics of the Australian Plate, edited by R. Hillis and D. Müller, pp. 203-221, Geol. Societies of Australia and Am, special paper 372 .

Swain, C. J., and J. F. Kirby (2006), An effective elastic thickness map of Australia from wavelet transforms of gravity and topography using Forsyth's method, Geophys. Res. Lett., 33, L02314, doi:10.1029/ 2005GL025090.

van der Beek, P. A., J. Braun, and K. Lambeck (1999), Post-Palaeozoic uplift history of southeastern Australia revisited: Results from a process-based model of landscape evolution, Aust. J. Earth Sci., 46, $157-172$

van der Hilst, R. D., B. L. N. Kennett, and T. Shibutan (1998), Upper mantle structure beneath Australia from portable array deployments, in Structure and Evolution of the Australian Continent, edited by J. Braun et al., AGU Geodynamics Monograph 26.

Vinnik, L. P., L. I. Makeyeva, A. Milev, and A. Y. Usenko (1992), Global patterns of azimuthal anisotropy and deformations in the continental mantle, Geophys. J. Int., 111, 433-447.

Wang, Z., and F. A. Dahlen (1995), Spherical-spline parameterization of three-dimensional Earth models, Geophys. Res. Lett., 22, 3099-3102.

Wellman, P. (1983), Hotspot volcanism in Australia and New Zealand: Cainozoic and mid-Mesozoic, Tectonophysics, 96, 225-243.

Wellman, P. (1987), Eastern Highlands of Australia their uplift and erosion, BMR J. Aust. Geol. Geophys., 10, 277-286.

White, R. S. (1999), The lithosphere under stress, Philos. Trans. R. Soc. Lond., 357, $901-915$.

Yoshizawa, K. (2002), Development and application of new techniques for surface wave tomography, Ph.D. dissertation, Australian National University, Acton, ACT, Australia.

Yoshizawa, K., and B. L. N. Kennett (2004), Multimode surface wave tomography for the Australian region using a three-stage approach incorporating finite frequency effects, J. Geophys. Res., 109, B02310, doi:10.1029/2002JB002254.

Zielhuis, A., and R. D. van der Hilst (1996), Uppermantle shear velocity beneath eastern Australia from inversion of waveforms from SKIPPY portable arrays, Geophys. J. Int., 127, 1-16.

Zuber, M. T., T. D. Bechtel, and D. W. Forsyth (1989), Effective elastic thickness of the lithosphere and the mechanisms of isostatic compensation in Australia, J. Geophys. Res., 94, 9353-9366.

S. Fishwick, Department of Geology, University of Leicester, University Road, Leicester LE1 7RH, UK. (sf130@le.ac.uk)

M. Heintz, Bullard Laboratories, Department of Earth Sciences, University of Cambridge, Cambridge, UK.

B. L. N. Kennett, Research School of Earth Sciences, Australian National University, Canberra, ACT 0200, Australia.

A. M. Reading, School of Earth Sciences and Centre of Excellence in Ore Deposit Research, University of Tasmania, Hobart, Tas 7001, Australia.

K. Yoshizawa, Department of Natural History Sciences, Faculty of Science, Hokkaido University, Sapporo 060-0810, Japan. 